\title{
Model Pembelajaran Kooperatif Tipe Kancing Gemerincing Terhadap Pemahaman Siswa Ekonomi
}

Oleh: Nurasmawi, Ristiliana, Suci Nofrianti

Pendidikan Ekonomi Fakultas Tarbiyah dan Keguruan

Universitas Islam Negeri Sultan Syarif Kasim Riau

Email: uinsuskanurasmawi@gmail.com, ristiliana@uin-suska.ac.id

\begin{abstract}
Abstrak
Tujuan penelitian ini adalah untuk mengetahui pengaruh model pembelajaran kooperatif tipe kancing gemerincing terhadap pemahaman siswa pada mata pelajaran ekonomi. Penelitian ini merupakan penelitian quasi eksperimen, sampel penelitian ini terdiri dari kelas eksperimen dan kelas control. Teknik pengumpulan data yang digunakan adalah observasi, test, dan dokumentasi. Teknik analisis yang digunakan untuk menguji hipotesis dalam penelitian ini adalah test " $\mathrm{t}$ ". Berdasarkan analisis uji $\mathrm{t}$ diketahui $\mathrm{t}_{\text {hitung }}$ atau $\mathrm{t}_{\mathrm{o}}=2,622$ lebih besar dari $t_{\text {tabel }}$ pada taraf signifikan $5 \%(2,622>2,000)$, berarti ada pengaruh yang signifikan pada pemahaman siswa antara siswa kelas eksperimen yang menerapkan model pembelajaran kooperatif kancing gemerincing dengan kelas kontrol yang tidak menerapkan model pada mata pelajaran ekonomi.
\end{abstract}

Kata Kunci: Model Pembelajaran kooperatif; Kancing Gemerincing; Pemahaman Siswa

\begin{abstract}
The purpose of this research was to determine effect impelementation cooperative learning model by using learning rattling buttons and students understanding in economics subjects. This research is a quasiexperimental study,the sample in this study consist is the experimental class and the control class. The data collection techniques used were observation, test, and documentation. Analytical techniques used to test the hypothesis in this research was $t$ test. Based on the analysis of t-test it was known that t-test score of 2,622 was greater than t-table at 5\% significant level $(2,622>2,000)$, This means that there was significant differences in the students' understanding of economic subjects between students who implemented cooperative learning of rattling buttons model with a class that does not implement cooperative learning of rattling buttons model.
\end{abstract}

Keywords: Cooperative Learning Model; Learning Rattling Buttons; Students Understanding. 


\section{PENDAHULUAN}

Pemahaman adalah kesanggupan untuk menyatakan defenisi, rumusan, kata yang sulit dengan perkataannya sendiri. Dapat pula merupakan kesanggupan untuk menafsirkan, menyelesaikan soal yang berkaitan atau melihat konsekuensi, meramalkan kemungkinan atau akibat sesuatu. (Usman, 2002: 51).

Menurut Benyamin S. Bloom pemahaman adalah kemampuan untuk menginterprestasikan atau mengulang informasi dengan menggunakan bahasa sendiri. (Djaali, 2009: 77). Pengertian pemahaman lain menurut Sardiman (2008: 43) yaitu menguasai sesuatu dengan pikiran. Karena itu belajar berarti harus mengerti secara mental makna dan filosofinya, maksud dan implikasi serta aplikasi-aplikasinya, sehingga menyebabkan siswa dapat memahami suatu situasi. Hal ini sangat penting bagi siswa yang belajar. Memahami maksudnya dan menangkap maknanya adalah tujuan akhir dari setiap belajar.

Pemahaman memiliki indikator yang dapat dijabarkan menjadi tiga yaitu: Menerjemahkan, Mengeinterpretasikan dan Mengekstrapolasi. (Daryanto, 2008: 107). Sedangkan menurut Noraini Idris (2005: 21) mengatakan bahwa ciri-ciri yang menunjukkan kepemahaman para pelajar tentang sesuatu adalah dapat menerangkan, dapat menggunakan dalam situasi yang lain dan dapat memberikan anggaran untuk menyimak kesesuaian jawaban serta dapat menyelesaikan soal.

Menurut Oemar Hamalik (2002: 209), pemahaman dapat diukur melalui tes lisan dan tulisan. Teknik penilaian penelitian aspek pemahaman caranya dengan mengajukan pertanyaan yang betul dan keliru, kesimpulan dan klasifikasi, dengan daftar pernyataan menjodohkan yang berkenaan dengan konsep, contoh, aturan, penerapan, langkah dan urutan dengan pertanyaan berbentuk essay (open ended) yang menghendaki uraian perumusan kembali dengan kata-kata sendiri dan contohcontoh.

Pemahaman siswa dalam belajar tidak hanya sekedar tahu tapi siswa juga harus benar-benar menguasai pelajaran, agar pengetahuan yang diperolehnya akan tetap bertahan lama dalam ingatannya. Tetapi dalam kenyataannya banyak siswa pada waktu proses belajar mengajar hanya sekedar mengetahui konsep saja, sehingga cenderung lupa apabila ditanya pada pertemuan berikutnya. Hal ini menunjukkan siswa sebagai subjek belajar tidak memiliki pemahaman terhadap pelajaran secara menyeluruh.

Berdasarkan fenomena yang ditemukan di lapangan, diperoleh informasi bahwa pada saat pembelajaran guru masih sering menggunakan metode konvensional. Seperti guru menggunakan metode ceramah, tanya jawab dan pemberian tugas, dan kadang- 
kadang menyelingi pembelajaran dengan metode diskusi kelompok. Namun metode tersebut nampaknya belum banyak membantu dalam meningkatkan pemahaman siswa. Hal ini dikarenakan dalam proses belajar mengajar terlihat hanya sebagian kecil siswa yang mau bertanya jika mengalami kesulitan dalam memahami penjelasan yang diberikan guru. Selama diskusi berlangsung, siswa hanya mengandalkan beberapa orang yang pintar dalam kelompok mereka untuk menjawab, bertanya dan menanggapi.

Fakta yang ditemukan ini menunjukkan bahwa pemahaman siswa pada mata pelajaran ekonomi di Kelas X SMA Negeri 1 Tambang masih rendah, yang terlihat dari masih ada siswa yang tidak dapat menjelaskan kembali apa yang telah diterangkan guru, masih ada siswa tidak dapat menjawab soal yang diberikan guru, masih ada siswa mencontek saat diberikan tugas oleh guru dan masih ada siswa tidak bisa menjelaskan materi pelajaran dengan kata-katanya sendiri.

Tinggi rendahnya pemahaman siswa diketahui sangat dipengaruhi oleh model pembelajaran yang dipakai oleh guru yang bersangkutan. Salah satunya model pembelajaran kooperatif. Model Pembelajaran Kooperatif adalah salah satu model pembelajaran yang dapat meningkatkan aktifitas siswa, meningkatkan daya nalar, cara berfikir logis, aktif, kreatif, terbuka, ingin tahu. Selain itu model ini mampu meningkatkan interaksi, meningkatkan penguasaan materi dan meningkatkan motivasi siswa untuk aktif dalam proses pembelajaran.

Alternatif model pembelajaran yang diharapkan dapat membantu siswa dalam memahami materi pelajaran adalah model pembelajaran Kooperatif Tipe Kancing Gemerincing. Model pembelajaran tipe Kancing Gemerincing ini dikembangkan oleh Speiker Kagan, di mana masing-masing anggota kelompok mendapatkan kesempatan untuk memberikan kontribusi mereka dan mendengarkan pandangan dan pemikiran orang lain. (Isjoni, 2010: 79).

Penerapan model pembelajaran tipe Kancing Gemerincing memiliki langkahlangkah seperti: guru menyiapkan satu kotak kecil yang berisi kancing-kancing; sebelum kelompok memulai tugasnya, setiap siswa dalam masing-masing kelompok mendapatkan dua atau tiga buah kancing; setiap kali seorang siswa berbicara atau mengeluarkan pendapat, dia harus menyerahkan salah satu kancingnya dan meletakkannya di tengah-tengah meja; jika kancing yang dimiliki seorang siswa habis, dia tidak boleh berbicara lagi sampai semua rekannya juga menghabiskan kancing mereka; jika semua kancing sudah habis, sedangkan tugas belum selesai, kelompok boleh mengambil kesempatan untuk membagibagi kancing lagi dan mengulangi prosedurnya kembali (Anita Lie, 2002: 63).

Oleh karena itu model ini cocok untuk mengaktifkan siswa yang pasif dan pemerataan kesempatan dalam pembelajaran. 
Karena salah satu keunggulan dari model ini adalah untuk mengatasi hambatan pemerataan kesempatan yang sering mewarnai kerja kelompok dan setiap siswa mendapatkan kesempatan untuk berperan serta.

Wina Sanjaya (2005: 79) mengatakan dengan model kancing gemerincing ini siswa tidak lagi di anggap sebagai objek belajar yang dapat diatur dan dibatasi oleh kemampuan guru, melainkan siswa di tempatkan sebagai subjek yang belajar sesuai dengan bakat, minat dan kemampuan yang dimiliknya. Oleh sebab itu, materi apa yang seharusnya dipelajari dan bagaimana cara mempelajarinya tidak sematamata di tentukan oleh keinginan guru, akan tetapi memperlihatkan perbedaan setiap siswa.

Berdasarkan latar belakang di atas, maka penelitian ini bertujuan untuk mengetahui bagaimana Pengaruh Penggunaan Model Pembelajaran Kooperatif Tipe Kancing Gemerincing terhadap Pemahaman Siswa pada Mata Pelajaran Ekonomi pada siswa kelas X SMAN 1 Tambang. Sedangkan rumusan masalah pada penelitian ini yaitu apakah terdapat perbedaan pemahaman siswa pada mata pelajaran ekonomi antara siswa yang menggunakan pembelajaran kooperatif tipe kancing gemerincing dengan siswa yang menggunakan pembelajaran konvensional.

\section{METODE PENELITIAN}

\section{Jenis Penelitian}

Penelitian ini merupakan penelitian quasi eksperimen dengan memberikan perlakuan. Adapun perlakuan dalam penelitian ini adalah pembelajaran kooperatif tipe kancing gemerincing sedangkan variabel yang diamati adalah pemahaman siswa. Desain penelitian yang digunakan adalah desain quasi ekperimental dengan bentuk Nonequivalent Control Group Design. (Sugiyono, 2012: 114).

\section{Waktu dan Tempat Penelitian}

Penelitian ini dilaksanakan di SMA Negeri 1 Tambang Kabupaten Kampar. Penelitian ini dilakukan dari bulan Maret sampai September 2014.

\section{Populasi dan Sampel Penelitian}

Populasi pada penelitian ini adalah seluruh siswa di SMA N 1 Tambang tahun ajaran 2014/2015 yang berjumlah 558 orang. Sampel yang diambil dalam penelitian ini adalah siswa kelas X IPS 2 dan X IPS 3 yang masing-masing kelas berjumlah 27 orang. Penentuan sampel kelas dilakukan berdasarkan rekomendasi guru bidang studi ekonomi. Untuk menentukan kelas eksperimen dan kelas kontrol dilakukan dengan pengundian sederhana, sehingga terpilihlah kelas X IPS 3 sebagai kelas eksperimen yang akan diberi perlakuan dengan model pembelajaran kooperatif kancing gemerincing dan kelas XIIS 2 sebagai kelas kontrol dengan pembelajaran konvensional.

\section{Prosedur Penelitian}

Desain quasi ekperimental dalam penelitian yaitu Nonequivalent Control Group Design. Prosedur pertama dalam penelitian ini 
adalah memilih kelas eksperimen dan kelas control. Kelompok kelas eksperimen yaitu kelompok yang memperoleh perlakuan pembelajaran kooperatif tipe kancing gemerincing. Kelompok kelas kontrol yaitu kelompok yang tidak memperoleh perlakuan atau kelompok yang memperoleh pembelajaran ekonomi secara konvesional. Gambaran tentang desain ini dapat dilihat pada gambar dibawah ini: (Sugiyono, 2012: 114).

$\begin{array}{lll}\mathrm{O}_{1} & \mathrm{X} 1 & \mathrm{O}_{2} \\ \mathrm{O}_{3} & & \mathrm{O}_{4}\end{array}$

dengan $\mathrm{O}_{1.3}$ : Pretest (Tes Awal)

X : Perlakuan pembelajaran ekonomi melalui pembelajaran kooperatif tipe kancing gemerincing.

$\mathrm{O}_{2.4}$ : Posttest (Tes Akhir)

\section{Teknik Pengumpulan Data}

Teknik yang digunakan untuk mengumpulkan data dalam penelitian ini antara lain:

- Tes: yaitu tes awal (pretest) dan tes akhir (posttest). Tes awal dilakukan untuk mengetahui kemampuan siswa kelas eksperimen dan kelas kontrol sebelum mendapat perlakuan, sementara tes akhir bertujuan untuk mengetahui pemahaman siswa setelah mendapatkan perlakuan. Tes ini terlebih dahulu harus diuji tingkat validitas, reliabilitas, daya pembeda, dan tingkat kesukaran.

- Observasi dilakukan untuk mengetahui tingkat aktivitas guru tersebut dalam pembelajaran diberikan rentang nilai 5 (sangat sempurna) hingga 1 (tidak sempurna).

- Dokumentasi, digunakan untuk mengumpulkan data terkait penelitian di SMAN 1 Tambang Kabupaten Kampar.

\section{Teknik Analisis Data}

Teknik analisis data yang digunakan dalam penelitian ini adalah Tes " $\mathrm{t}$ ". Tes " $\mathrm{t}$ " merupakan salah satu uji statistik yang digunakan untuk mengetahui ada atau tidaknya perbedaan yang signifikan dari dua buah mean sampel (dua buah variabel yang dikomparatifkan). Namun penggunaan tes " $t$ " tersebut harus memenuhi dua syarat yaitu uji normalitas dan homogenitas.

Rumus tes " $t$ " yaitu (Hartono, 2008: 207):

$$
t_{0}=\frac{M_{x}-M_{y}}{\sqrt{\left[\frac{S D_{x}}{\sqrt{N-1}}\right]^{2}+\left[\frac{S D_{y}}{\sqrt{N-1}}\right]^{2}}}
$$

Keterangan :

$M_{x}=$ Mean variabel $\mathrm{x}$

$M_{y}=$ Mean variabel $\mathrm{y}$

$S D_{x}=$ Standar deviasi $\mathrm{x}$

$S D_{y}=$ Standar deviasi $\mathrm{y}$

$\mathrm{N}=$ Jumlah sampel.

Apabila diperoleh analisis data tes " $\mathrm{t}$ " $t_{\text {hitung }} \geq t_{\text {tabel }}$, artinya ada perbedaan yang signifikan apabila pembelajaran kooperatif tipe kancing gemerincing diimplementasikan dalam mata pelajaran ekonomi. Sebaliknya apabila $t_{\text {hitung }}<t_{\text {tabel }}$, artinya tidak ada perbedaan yang signifikan apabila 
pembelajaran kooperatif tipe kancing gemerincing diimplementasikan.

\section{HASIL PENELITIAN DAN PEMBAHASAN}

Berdasarkan hasil penelitian yang telah dilakukan sebanyak 3 (tiga) kali pertemuan tentang aktivitas guru menerapkan model pembelajaran tipe kancing gemerincing, dan menilai pemahaman siswa atas materi yang telah disampaikan di kelas eksperimen dan model pembelajaran konvensional diterapkan di kelas control. Perlakuan di kelas eksperimen dan kelas control sama-sama diberikan pretest sebelum diterapkan model, dan setelahnya diberikan posttest supaya terlihat perbedaan pada pemahaman siswa sebelum dan setelah diterapkan model baik itu tipe kancing gemerincing ataupun konvensional.

Berdasarkan hasil Uji T Pretest bahwa tidak terdapat perbedaan yang signifikan skor pretest dari pemahaman siswa pada mata pelajaran ekonomi pada kedua kelas. Artinya antara kelas eksperimen dan kontrol memiliki kemampuan awal yang sama, berarti penelitian ini dapat dilanjutkan, di mana siswa kelas XII S3 sebagai kelas eksperimen dan digunakan model pembelajaran kooperatif kancing gemerincing selanjutnya kelas XII S2 sebagai kelas kontrol dan diberikan perlakuan seperti proses belajar mengajar konvensional.

Berdasarkan hasil Uji T Posttest pada kedua kelas yaitu kelas eksperimen dan kontrol terdapat perbedaan pemahaman antara siswa yang menggunakan pembelajaran kooperatif tipe kancing gemerincing dengan siswa yang menggunakan pembelajaran konvesional.

\section{Pengaruh Penerapan Model Pembelajaran} Kooperatif Tipe Kancing Gemerincing terhadap Pemahaman Siswa

Setelah dilakukan analisis data, dan berdasarkan hasil pengujian hipotesis yang diperoleh menunjukkan bahwa penggunaan model pembelajaran kooperatif kancing gemerincing mempunyai pengaruh terhadap pemahaman siswa pada mata pelajaran ekonomi. Dilihat dari hasil uji perbedaan ratarata, siswa dari kelas eksperimen dan kelas kontrol memiliki kemampuan awal yang sama, atau tidak terdapat perbedaan yang signifikan. Hasil juga dilihat dari perhitungan uji t dari kelas eksperimen dengan kelas kontrol yang memiliki $t_{\text {hitung }} 0,4339$ lebih kecil $t_{\text {tabel }} 2,000$.

Berdasarkan hasil analisis terhadap skor postest, diketahui bahwa siswa yang belajar menggunakan model pembelajaran kooperatif kancing gemerincing kelas eksperimen memiliki rata-rata posttest sebesar 76,33 dengan standar deviasi 10,983sedangkan kelas kontrol memiliki rata-rata postest sebesar 68,04 dengan standar deviasi 12,23. Berdasarkan perbedaan rata-rata tersebut dapat disimpulkan bahwa terdapat perbedaan pemahaman siswa pada mata pelajaran ekonomi dengan menggunakan model pembelajaran kooperatif kancing gemerincing dengan siswa yang belajar menggunakan model konvensonal. Jadi penggunaan model 
pembelajaran kooperatif kancing gemerincing dalam memberikan pemahaman siswa pada mata pelajaran ekonomi lebih baik daripada menggunakan model pembelajaran konvensional.

Perbedaan ini didasarkan setelah adanya uji perbedaan antara kelas eksperimen dan kelas kontrol dengan menggunakan uji-t. Hasil perhitungan uji-t diperoleh bahwa $t_{\text {hitung }} 2,622$ lebih besar dari $t_{\text {tabel }} 2,000$. Artinya dengan menerapkan model pembelajaran kooperatif kancing gemerincing, maka pemahaman siswa kelas X SMA N 1 Tambang Kabupaten Kampar akan meningkat dan pembelajarannya menjadi lebih efektif.

Selanjutnya untuk menghitung pengaruh pembelajaran kooperatif tipe kancing gemerincing terhadap pemahaman siswa, dapat dilakukan dengan menghitung koefisien $\left(\mathrm{r}^{2}\right)$ menggunakan rumus:

$$
\begin{aligned}
T_{\text {hitung }} & =r \frac{\sqrt{n-2}}{1-r^{2}} \text { atau } r^{2}=\frac{t^{2}}{t^{2}+n-1} \\
r^{2} & =\frac{t^{2}}{t^{2}+n-1} \\
& =\frac{(2,62)^{2}}{2,62^{2}+27-2} \\
& =\frac{6,8644}{6,8644+25} \\
& =\frac{6,8644}{31,8644} \\
& =0,215
\end{aligned}
$$

Setelah itu, untuk mencari besarnya sumbangan (kontribusi) variabel X terhadap Y digunakan rumus:

$$
\begin{aligned}
\mathrm{KP} & =r^{2} \times 100 \% \\
& =0,215 \times 100 \% \\
& =21,54 \%
\end{aligned}
$$

Artinya variabel penggunaan model pembelajaran kooperatif tipe kancing gemerincing memberikan kontribusi terhadap pemahaman siswa pada mata pelajaran ekonomi sebesar $21,54 \%$ dan sisanya ditentukan oleh variabel lain.

Berdasarkan kontribusi tersebut, maka dapat disimpulkan bahwa melalui model pembelajaran kooperatif tipe kancing gemerincing siswa memperoleh banyak kesempatan untuk berdiskusi dan berbagi informasi dengan anggota kelompok. Mereka bersama-sama ikut berperan aktif untuk menyelesaikan permasalahan yang diberikan. Hasil analisis ini mendukung rumusan masalah yang diajukan yaitu terdapat perbedaan pemahaman antara siswa yang belajar menggunakan model pembelajaran kooperatif tipe kancing gemerincing dengan siswa yang menggunakan model pembelajaran konvensional. Artinya penerapan model pembelajaran kooperatif tipe kancing gemerincing berpengaruh terhadap pemahaman siswa pada mata pelajaran ekonomi di Kelas X SMA Negeri 1 Tambang Kabupaten Kampar.

\section{SIMPULAN DAN SARAN}

\section{Simpulan}

1. Model pembelajaran kooperatif tipe kancing gemerincing dapat mempengaruhi pemahaman siswa. Hasil ini dibuktikan dengan hasil tes siswa kelas eksperimen lebih tinggi dibanding kelas kontrol yaitu 
rata-rata hasil tes siswa pada kelas eksperimen sebesar 76,33 lebih tinggi dibandingkan hasil tes siswa pada kelas kontrol yaitu sebesar 68,04.

2. Berdasarkan analisis uji $\mathrm{t}$ diketahui $\mathrm{t}_{\text {hitung }}$ atau $t_{0}=2,622$ lebih besar dari $t_{\text {tabel }}$ pada taraf signifikan $5 \%(2,622>2,000)$, ini berarti ada perbedaan yang signifikan pemahaman siswa pada mata pelajaran ekonomi di kelas $\mathrm{X}$, antara siswa kelas eksperimen (menggunakan model pembelajaran kooperatif tipe kancing gemerincing) dengan kelas control (menggunakan model pembelajaran konvensional) di SMA Negeri 1 Tambang Kabupaten Kampar. Berdasarkan perbedaan tersebut berarti ada pengaruh yang signifikan antara penggunaan model pembelajaran kooperatif tipe kancing gemerincing terhadap pemahaman siswa pada mata pelajaran ekonomi di kelas $\mathrm{X}$ SMA N 1 Tambang Kabupaten Kampar.

\section{Saran}

Berdasarkan kesimpulan dari penelitian ini, dapat dikemukakan saran-saran sebagai berikut:

1. Selama melaksanakan proses pembelajaran di kelas, guru dapat menggunakan bermacam model pembelajaran kooperatif secara bervariasi, agar siswa tidak bosan.

2. Ketika akan menggunakan model pembelajaran kooperatif tipe kancing gemerincing sebaiknya guru melakukan persiapan yang maksimal sehingga proses pembelajaran berjalan lancar dan efektif sesuai dengan alokasi waktu.

3. Guru hendaknya dapat membiasakan siswa untuk berintekrasi dan bekerjasama dengan temannya dalam proses diskusi agar siswa lebih mudah memahami materi yang dipelajari.

4. Bagi siswa dalam mempelajari materi pembelajaran sebaiknya membiasakan diri untuk mencoba menyelesaikan masalah dengan kemampuan sendiri agar siswa dapat berfikir dan mampu memahami maksud dari materi pembelajaran yang disampaikan.

\section{DAFTAR PUSTAKA}

Anita Lie. 2002. Cooperative Learning. Jakarta: PT Gramedia Widiasarana Indonesia.

Daryanto. 2008. Evaluasi Pendidikan. Jakarta: Rineka Cipta.

Djaali. 2009. Psikologi Pendidikan. Jakarta: Bumi Aksara.

Hartono. 2008. Statistik Untuk Penelitian. Yogyakarta: Pustaka Pelajar.

Isjoni. 2010. Cooperative Learning. Bandung: Alfabeta.

Noraini Idris. 2005. Pedagogi dalam Pendidikan Matematika. Kuala lumpur: utusan Publications \& Distributors SDN BHN.

Oemar Hamalik. 2002. Psikologi Belajar Mengajar. Bandung: Sinar baru Algesindo.

Sardiman A.M, 2008. Interaksi \& Motivasi Belajar Mengajar. Jakarta: Raja Grafindo Persada. 
EKLEKTIK : Jurnal Pendidikan Ekonomi dan Kewirausahaan

Volume 1 Nomor 2 Tahun 2018

Sugiyono. 2011. Metode Penelitian Kuantitatif Kualitatif dan $R$ \& $D$. Bandung: Alfabeta.

Usman Basuki Aswawir. 2002. Media Pembelajaran. Padang: Ciputat Press.

Wina Sanjana. 2005. Kurikulum dan Pembelajaran. Jakarta: Kencana Prenada Media Group. 